\title{
PHÂN TÍCH CÁC BÊN LIÊN QUAN ĐẾN CHƯƠNG TRÌNH SÀNG LỌC UNG THƯ ĐẠI TRỰC TRÀNG TẠI VIỆT NAM
}

\section{TÓM TĂT}

Mục tiêu: Phân tích các bên liên quan đến hoạt động sàng lọc ung thư đại trực tràng tại Việt Nam. Phương pháp nghiên cứu: Nighiên cứu định tính sử dung kỹ thuâtt thảo luân nhóm (8 cuộc thảo luân nhóm) và tổng quan tài liệu. Kết quả và kết luận: Kết quả nghiên cứu cho thấy các bên liên quan đến chương trình sàng lọc từ trung ương đến địa phương, bao gồm Bộ y tế; bệnh viện $K$ trung ương, bộ tài chính và bộ kế hoạch đầu tư; bảo hiểm xã hội Việt Nam. Ở tuyến tỉnh, ủy ban nhân dân các tỉnh/thành phố, trung tâm kiểm soát bệnh tật/trung tâm y tế dự phòng tuyến tỉnh, bệnh viện tuyến tỉnhvà tuyến trung ương. Ớ tuyến xã/phường, vai trò của các trạm y tế xã/phường được nhấn manh trong viêc triển khai hoạt động cùng với mạng lưới cộng tác viên/y tế thôn bản.

Tư khoá: Sàng lọc, ung thư đại trực tràng, các bên liên quan, Việt Nam

\section{SUMMARY}

ANALYSIS OF STAKEHOLDER REGARDING TO THE COLORECTAL CANCER SCREENING

\section{IN VIETNAM}

Objective: To analyze stakeholders in colorectal cancer screening in Vietnam. Methods: Qualitative research using focus group discussions (8 group discussions) and document review techniques. Results and Conclusions: Research results show that stakeholders regarding to the colorectal cancer screening in Vietnam from the central to local levels, including the Ministry of Health; Vietnam National Cancer Hospital, Ministry of Finance and Ministry of Planning and Investment; Vietnam social insurance. At the provincial level, provincial People's Committees, disease control centers/provincial preventive medicine centers, provincial and central hospitals. At the communelevel, the role of communehealth stations was emphasized in implementing activities with the network of collaborators ofvillage health workers.

Keywords: colorectal cancer, screening, stakehoders, Vietnam

\section{I. ĐĂT VẤN ĐỀ}

Ung thư đai trực tràng là ung thư phổ biến thứ ba ở nam giới và phổ biến thứ hai ở nữ giới (1). Cùng với các nhóm ung thư khác, ung thư đại trực tràng trở thành một trong những nguyên nhân hàng đầu của gánh nặng bệnh tật

*Trường Đại học Y tế Công Cộng

Chịu trách nhiệm chính: Nguyễn Quỳnh Anh

Email: nqa@huph.edu.vn

Ngày nhận bài: 19.2.2021

Ngày phản biên khoa học: 30.3.2021

Ngày duyệt bài: 8.4.2021

\section{Nguyễn Quỳnh Anh*, Nguyễn Thu Hà*}

và tử vong tai Viêt Nam. Đó là lý do vì sao mà việc đầu tư cho sàng lọc ung thư đại trực tràng ở Việt Nam đã được khẳng định về mặt chủ trương thồng qua phê duyêt của Dư án chủ đông dự phòng, phát hiện sớm, chẩn đoán, điều trị, quản lý bệnh ung thư, tim mạch, đái tháo đường, bệnh phổi tắc nghẽn man tính, hen phế quản và các bệnh không lây nhiểm khác, giai đoạn 20162020, trong đó dự án hướng tới mục tiêu $20 \%$ số người mắc ung thư khoang miệng, vú, cổ tử cung, buồng trứng, đại trực tràng được phát hiện ở giai đoạn sớm.

Tuy nhiên, đến thời điểm hiện tại, sàng loc ung thư đại trực tràng ở Việt Nam mới chỉ diển ra thí điểm ở một số tỉnh thành phố lớn (2).Mặc dù tính chi phí - hiệu quả của sàng lọc ung thư đại trực tràng là không phải bàn cãi, khi nhiều đánh giá kinh tế y tế cũng như các tổng quan hệ thống đã nhấn mạnh tính tiết kiệm về chi phí cũng như chi phí - hiệu quả của việc thực hiện bất kì chương trình sàng lọc ung thư đại trực tràng - sử dụng bất kì xét nghiệm sàng lọc nào so sánh với không triển khai sàng lọc ung thư đại trực tràng, việc triển khai một chương trình sàng lọc tương tự tai Viêt Nam vẫn chưa được thực hiện. Để có thể triển khai được chương trình sàng lọc ung thư đại trực tràng một cách hiệu quả tại Việt Nam, việc tìm hiểu vai trò của các bên liên quan đên chương trình sàng lọc là vô cùng quan trọng. Do vậy, chúng tôi thực hiện nghiên cứu "Phân tích các bên liên quan đến hoạt động sàng loc ung thu đại trực tràng tại Việt Nam".

\section{II. ĐỐI TƯợNG VÀ PHƯƠNG PHÁP NGHIÊN CỨU}

Thiết kế nghiên cứu: Nghiên cứu định tính sử dụng kỹ thuật phỏng vấn sâu và thảo luận nhóm với các bên liên quan và tổng quan tài liệu để xác định các bên liên quan đến hoạt động sàng lọc ung thư đại trực tràng tại Việt Nam.

Chủ đề nghiên cứu định tính: Tiến hành liêt kê các bên liên quan đển việc triển khai can thiệp sàng lọc ung thư đại trực tràng; phỏng vấn sâu để xác định mối liên hệ với can thiệp, mở rộng/thu hẹp các bên liên quan.

Phương pháp thu thập số liệu: Tiến hành 8 cuộc thảo luận nhóm (TLN) với 6 nhóm đối tượng,bao gồm: Dự án phòng chống ung thư Việt Nam; Bệnh viện chuyên khoa tuyến Trung 
ương; Cơ sở y tế tuyến tỉnh; Cơ sở y tế tuyến quận/huyện; Trạm y tễ xã/phường; Người dân từ 50-70 tuổi, sử dụng bộ câu hỏi hướng dẫn PVS/TLN xây dựng trước

Phương pháp phân tích: Tiến hành gõ băng, mã hóa đối tượng tham gia PVS/TLN vàphân tích số liệu theo nhóm chủ đề

Đạo đức trong nghiên cứu: Nghiên cứu được tiến hành sau khi Hội đồng Đạo đức Nghiên cứu Y Sinh học trường Đại học Y tế công cộng xem xét và phê duyệt thông qua theo công văn số 455/2018/YTCC-HD3 ngày 7/11/2018.

\section{KẾT QUẢ NGHIÊN CỨU}

Kết quả tổng quan các tài liệu thứ cấp bao gồm: (1) văn kiện Dự án chủ động dự phòng phát hiện sớm, chẩn đoán điều trị, quản lý các bệnh ung thư, tim mạch đái tháo đường, bệnh phổi tắc nghẽn mạn tính và hen phế quản, giai đoạn 2015-2020 (Chiến lược quốc gia phòng chống bệnh không lây nhiếm giai đoạn 20152025 ban hành kèm theo Quyết định 376/QĐ-Tg ngày 20/3/2015); (2) Quyết định 3338/QĐ-BYT ngày 09 tháng 9 năm 2013 của Bộ trưởng Bộ y tế về việc Ban hành hướng dẫn Quy trình kỹ thuật khám bệnh, chữa bệnh chuyên ngành Ung bướu (Trong đó có Sàng lọc phát hiện sớm ung thư đại trực tràng); (3) Quyết định số 3756/QĐBYT ngày 21 tháng 6 năm 2018 cửa Bộ trưởng Bộ y tế về việc ban hành hướng dẫn hoạt động dự phòng, phát hiện sớm, chẩn đoán, điều trị và quản lý một số bệnh không lây nhiễm phổ biến cho tuyến y tế cơ sở; và (4) Quy trình sàng lọc phát hiện sớm ung thư đại trực tràng thí điểm tại Hà Nội cho thấy một số bên liên quan đến can thiệp sàng lọc ung thư đại trực tràng tại cộng đồng, bao gồm Bộ y tế; cơ sở y tế tuyến trung ương; cơ sở y tế tuyến tỉnh; cơ sở y tế tuyến xã/phường và đội ngũ cộng tác viên và đối tượng đích.

Kết quả thảo luận nhóm cũng cho thấy các bên liên quan đến chương trình sàng lọc từ trung ương đến địa phương.

Ớ tuyến trung ương, kêt quả thảo luận nhóm cho thấy vai trò chủ trì của bộ y tế, cụ thể là ban chỉ đạo chương trình hay cụ thể hơn là bệnh viện $\mathrm{K}$ trung ương với vai trò điều phối chính của hoạt động:

"Nếu được triển khai một cách bài bản như các văn bản và chương trình được phê duyệt thì chương trình sàng lọc liên quan đến rất nhiều nhóm đối tượng từ trung ương đến địa phương. Từ trung ương nhìn chung đóng vai trò chính là ở bộ y tế. Thực tế chương trình mục tiêu y tế - dân số cũng có hoạt động phòng chống ung thư... cũng tập trung vào việc tổ chức khám sàng lọc ung thư tại cộng đồng....chiến lược quốc gia phòng chống bệnh không lây nhiễm giai đoạn 2015-2025 cũng có Dự án chủ động dự phòng phát hiện sớm... bệnh ung thư... Dù còn có sự chồng chéo nhưng vai trò chủ trì của Bộ $Y$ tế là thống nhất trong tất cả các dự án này. Bộ Y tế đã thành lập ban chỉ đạo chương trình phòng chống một số bệnh không lây nhiễm bao gồm thành viên từ các vụ cục, các bệnh viện chuyên khoa đầu ngành và tất nhiên đóng vai trò chỉ đạo từ phía tiểu dự án Ung thư chính là bệnh viện $\mathrm{K}$ trung ương" (TLN1, Dự án PCUT).

Bên cạnh vai trò chủ trì của ngành y tế, kết quả thảo luâan nhóm cũng đề cập đến vai trò của bộ tài chính và bộ kế hoạch đầu tư trong việc huy động nguồn lực triển khai chương trình, tương tự như nội dung đã được nêu trong một số quyết định của thủ tướng chính phủ trong việc triển khai hoạt động. Đồng thời cũng có ý kiến cho rằng vai trò của bảo hiểm xã hội Việt Nam trong tương lai cũng đóng vai trò quan trọng vì một trong những nguồn lực tài chính cơ bản được xác định để triển khai chương trình một cách bền vững và hiệu quả là nguồn bảo hiểm y tế, tuy nhiên việc sử dụng nguồn bảo hiểm y tế trong thời gian tới được nhận định là gặp nhiều khó khăn vì bối cảnh chính sách:

"...Để chương trình triển khai có hiệu quả trên quy mô toàn quốc thì rõ ràng vai trò của Bộ Kế hoạch đầu tư và Bộ Tài chính là rất quan trọng" (TLN1, Dự án PCUT)

"Trong tương lai cũng cần xem xét để nhìn nhận bảo hiểm xã hội như một trong những mắt xích quan trọng vì BHYT sửa đổi chi trả cho hoạt động sàng lọc thì đây cũng là một trong những bển liên quan quan trọng liên quan đến bền vững về mặt kinh phí cho chương trình" (TLN2, BVTW)

"Nếu chỉ trông chờ vào ngân sách nhà nước thì chắc chắn không khả thi, cần phải suy nghĩ làm thế nào để có thể vận động được kinh phí từ nguồn khác mà chủ trương rất rõ ràng rồi còn phải từ bảo hiểm y tế nữa và đóng góp của người dân. Bản thân bảo hiểm y tế hiện tại rất vướng để chi trả được cho hoạt động dự phòng. Vì luật BHYT nói rõ rồi, chỉ chi trả để điều trị chẩn đoán ko có chữ sàng lọc. Đây cũng là một trong những điểm mà phải vận động trong thời gian tới" (TLN1, Dự án PCUT)

Ở quy mô tuyến tỉnh, các đối tượng tham gia TLN cũng đánh giá vai trò quan trọng của ủy ban nhân dân các tỉnh/thành phố trong việc quyết định chủ trương triển khai chương trình sàng lọc: 
"Khi phân cấp quản lý về đến các tỉnh/thành phố thì vai trò của ủy ban nhân dân các tỉnh/thành phố trong xây dựng và chỉ đạo triển khai thực hiện chiến lược tại các địa phương" (TLN1, Dự án PCUT)

"Ở các tỉnh, thành phố thì để chương trình có thể triển khai được thì quan trọng trước tiên là chủ trương của ủy ban tỉnh" (TLN3, CSYT tỉnh, miền Bắc)

Các ý kiến trả lời TLN cũng cho thấy vai trò đầu mối của sở y tế trong việc quản lý triển khai và trung tâm kiểm soát bệnh tật/trung tâm y tế dự phòng tuyến tỉnh trong việc điều phối về mặt chuyên môn đối với hoạt động:

"Ở tuyến tỉnh, đâu mối hoạt động thuộc về các trung tâm kiểm soát bênh tật các tỉnh và sở y tế các tỉnh để hoạt động sàng lọc cộng đồng này được triển khai xuống các tuyến dưới. Tiếp theo đó đầu mối để triển khai rộng khắp xuống các huyện là các trung tâm y tế các huyện từ đó đi sâu rộng xuống các trạm y tế" (TLN1, Dự án PCUT)

"Sở y tế có đóng vai trò đầu mối tốt để Sở kế hoạch đâu tư và Sở tài chính xây dựng kế hoạch kinh phí và cấp kinh phí hoạt động thì các hoạt động mới hi vọng triển khai được. Sở y tế phải đóng vai trò đầu mối trong các hoạt động này, còn tất nhiên tỉnh nào đã sát nhập trung tâm kiểm soát bệnh tật thì các hoạt động chuyên môn chỉ đạo các tuyến dưới phải được thực hiện bởi CDC. CDC phải lên kế hoạch truyền thông như thế nào, dư trù dụng cư đựng mẩu phân ra sao, tâp huấn các cơ sở tuyến dưới như thế nào để triển khai được chương trình..... Hoạt động này hoàn toàn có thể làm tương tự như mô hình của các chương trình mục tiêu quốc gia. Như tiêm chủng đã làm nhiều năm dựa vào mạng lưới trạm y tê xã với sự chỉ đạo xuyên suốt của các trung tâm y tế, và của CDC các tỉnh" (TLN3, CSYT tỉnh, miên Bắc)

Các ý kiến trả lời cũng nhấn mạnh vai trò của các bệnh viện tuyến tỉnhvà tuyến trung ương trong việc thực hiện kỹ thuật xét nghiệm và nội soi đại trực tràng để đảm bảo tính chính xác của kỹ thuật sàng lọc cũng như đảm bảo hạn chế các biến chứng của nội soi đại trực tràng:

"...việc xét nghiệm được kết quả và trả kết quả cần được thực hiện ở các bệnh viện có đủ điều kiện máy móc trang thiết bị, nội soi đại trực tràng cũng tương tự như vậy cần có sự tham gia của các bệnh viện tuyến tỉnh và trung ương với nhân lực đảm bảo thực hiện được" (TLN2, BVTW)

"Các bệnh viện tuyến tỉnh đóng vai trò đầu mối của việc nội soi đại trực tràng vì thực sự chất lượng ở các bệnh viện tuyến quận huyện không thực sự như nhau mà điều này rất cần phải cân nhắc khi mà triển khai quy mô toàn quốc và việc nội soi không như xét nghiệm phân vẫn có thể xảy ra những sự cố không mong muốn như thủng đường tiêu hóa hay thường gặp nhất là chảy máu" (TLN3, CSYT tỉnh, miền Bắc)

Tuy nhiên, cũng có những ý kiến TLN cho rằng việc triển khai hoạt động nội soi đại trực tràng cũ̃ng như triển khai kỹ thuật sàng lọc hoàn toàn có thể được thực hiện tại các cơ sở y tế tuyễn huyện như các bệnh viện huyện hoặc các cơ sở y tế mà dịch vụ kỹ thuật được phê duyệt thực hiện nhằm đảm bảo khả năng tiếp cận của đối tượng:

"Hoạt động nội soi có thể thực hiện rất tốt ở nhiều bệnh viện trực thuộc sở chứ không cứ là bệnh viện tuyến tỉnh. Quan trọng là bệnh viện cứ được phê duyệt thực hiện dịch vụ kỹ thuật chứ không cứ là tuyến nào hạng nào. Nhiều bệnh viện huyện thậm chí phòng khám đa khoa có chất lượng rất tốt. Mục đích cuối cùng để người dân tiêp cận được tốt. Tât nhiên cần có đơn vị đầu mối ở các huyện các tỉnh và cơ chế về kinh phí để làm được việc này" (TLN4, CSYT tỉnh, miền Nam)

ớ quy mô tuyến tỉnh, các ý kiến trả lời thảo luận nhóm đều nhấn mạnh vai trò điều phối của các trung tâm y tế theo ngành dọc từ trung tâm kiểm soát bệnh tật/trung tâm y tế dự phòng tuyến tỉnh xuống các trung tâm y tế tương tự như các hoat động đã triển khai thuộc chương trình mục tiêu y tế - dân số:

"Cái này triển khai được ở huyện thì vai trò là các trung tâm y tế. Trung tâm y tế phải điều phối, ví du như tập huấn hướng dẫn cho các trạm y tế lấy mẫu phân như thế nào cho đúng, thu thập về chuyển đến đâu, bao nhiêu bộ đựng lập kế hoach ra sao. Trung tâm y tế tiếp nhân các ca dương tính chuyển lên để nội soi cũng phải ghi nhận như thế nào đơn vị nào làm nội soi cũng phải quy định rõ ràng" (TLN5, CSYT quận huyện, miền Bắc)

"...tram y tế không thể xét nghiệm ra mà chỉ đóng vai trò trung gian trả kết quả thôi. Không phải nơi nào cũng có máy móc, phải quy về trung tâm y tế làm hoạt động này chẳng hạn. Trung tâm y tế cũng phải là nơi tiếp nhận để nội soi đại trực tràng chẳng hạn. Các nơi mà trung tâm y tế một chức năng thì bệnh viện huyện được giao nhiệm vụ chẳng hạn chứ không thể là cơ sở nào cũng đước vì còn liên quan đến việc quản lý và chi trả" (TLN6, CSYT quận huyện, 
miền Nam)

Hoạt động đã triển khai trên địa bàn thành phố Hà Nội cũng cho thấy vai trò của trung tâm y tế trong việc "tập huấn" và "lập kế hoạch" triển khai hoạt động:

"Nếu triển khai hoạt động tương tự như hoạt động năm vừa rồi, chúng tôi (cán bộ TYT) được trung tâm y tế Hoàn Kiếm tập huấn phải làm các hoat động gì, tổng hợp số lượng bà con trong độ tuổi để lấy số lượng lọ đựng phân và tờ rới cho đúng" (LTN7, Trạm y tế)

ớ tuyến xã/phường, vai trò của các trạm y tế xã/phường được nhấn mạnh trong việc triển khai hoạt động:

"Nhìn chung chương trình sàng lọc sẽ liên quan đến các cán bộ y tế cơ sở sẽ triển khai cho người dân làm xét nghiệm tìm máu ẩn trong phân" (TLN2, BVTW)

"Để triển khai được chương trình ở quy mô toàn quốc thì đầu tiên là anh em cơ sở. Phải có cơ chế để triển khai, khi đã có cơ chế và chủ trương rồi, có kinh phí rồi thì là hoạt động thường quy của anh em" (TLN4, CSYT tỉnh, miền Nam)

"Liên quan đến hoạt động sàng lọc mà dự định triển khai toàn quốc thì trước hết là cơ sở ban đầu tiếp nhận, làm vận động truyền thông cho người dân hiểu mà đi sàng lọc" (TLN6, CSYT quận huyện, miền Nam)

Kết quả thảo luận nhóm với trạm y tế trên địa bàn thành phố Hà Nội cũng cho thây cơ chế triển khai tương tự và vai trò của các trạm y tế trong quá trình triển khai chương trình sàng lọc ung thư đại trực tràng ở quy mô cộng đồng miễn phí trong năm 2018:

"Các mẫu được tổng hợp như chúng tôi là chuyển đến bệnh Thu Cúc để phân tích, kết quả trả qua phần mềm. Chúng tôi nhận kết quả báo cho các tổ để ai thuộc diện dương tính thì động viên làm nội soi. Có suất làm nội soi miễn phí thì thông báo cho họ để họ chuẩn bị đi làm. Làm nội soi như vậy mà miễn phí thì theo thông báo của trung tâm y tế để đến làm" (TLN7, Trạm y tế)

"Chúng tôi nhận thông báo từ tổ dân phố, nhân lọ đựng và hướng dẫn lấy phân, không hiểu gì thì hỏi trạm y tế. Lây xong theo hướng dẫn thì mang đến trạm để họ làm xét nghiệm rồi hẹn lúc nào lấy kết quả thì lấy kết quả" (TLN8, người dân)

Bên cạnh đó, ngoài vai trò của cán bộ y tế các trạm y tế, kết quả thảo luận nhóm cũng cho thấy vai trò của mạng lưới cộng tác viên/y tế thôn bản trong việc hổ trợ triển khai hoạt động. Tùy từng khu vực mà các cộng tác viên là đội ngũ "y tế thôn bản", "hội phụ nữ", "hội người cao tuổi" hoặc đặc thù tại thành phố Hà Nội trong chương trình sàng lọc ung thư đại trực tràng miễn phí năm 2018 là đội ngũ "tổ trưởng/tổ phó dân phố":

"Sẽ thực hiện giống các hoạt động thường quy khác, phải lên kế hoạch hoạt động, dự trù kinh phí, tài liệu truyền thông như tờ rợ, bộ đựng mấu phân, xây dựng kế hoạch tập huấn kết hợp với cộng tác viên thôn bản hoặc trực tiếp với trưởng thôn. Thường anh em ở trạm không thể nào làm xuể hết phải có đội ngũ cộng tác viên. Tùy từng nơi mà cộng tác viên hay trưởng thôn hay phải là hội phụ nữ, hội người cao tuổi cùng đứng ra vận động giúp" (TLN6, CSYT quận huyện, miền Nam)

\section{BÀN LUẬN}

Kết quả tổng quan các tài liệu thứ cấp cho thấy một số bên liên quan đến can thiệp sàng lọc ung thư đại trực tràng tại cộng đồng, bao gồm Bộ $y$ tế; cở sở y tế tuyến trung ương; cơ sở y tế tuyến tỉnh; cơ sở y tế tuyến xã/phường và đội ngũ cộng tác viên và đối tượng đích. Ở tuyến trung ương, kết quả thảo luận nhóm cho thây vai trò chủ trì của bộ y tế, cụ thể là ban chỉ đạo chương trình hay cụ thể hơn là bệnh viện $\mathrm{K}$ trung ương với vai trò điều phối chính của hoạt động. Bên cạnh vai trò chủ trì của ngành y tế, kết quả thảo luận nhóm cũng đề cập đến vai trò của bộ tài chính và bộ kế hoạch đâu tư trong việc huy động nguồn lực triển khai chương trình, tương tự như nội dung đã được nêu trong một số quyết định của thủ tướng chính phủ trong việc triển khai hoạt động. Đồng thời cũng có ý kiến cho rằng vai trò của bảo hiểm xã hội Việt Nam trong tương lai cũng đóng vai trò quan trọng vì một trong những nguồn lực tài chính cơ bản được xác định để triển khai chương trình một cách bền vững và hiệu quả là nguồn bảo hiểm y tế.

Ở tuyến tỉnh, các đối tượng tham gia TLN cũng đánh giá vai trò quan trọng của ủy ban nhân dân các tỉnh/thành phố trong việc quyết định chủ trương triển khai chương trình sàng lọc, nhấn mạnh vai trò của các bệnh viện tuyến tỉnhvà tuyến trung ương trong việc thực hiện kỹ thuật xét nghiệm và nội soi đại trực tràng để đảm bảo tính chính xác của kỹ thuật sàng lọc cũng như đảm bảo hạn chế các biến chứng của nội șoi đại trực tràng.

Ở tuyến xã/phường, vai trò của các trạm y tế xã/phường được nhấn mạnh trong việc triển khai hoạt động. Bên cạnh đó, ngoài vai trò của cán bộ y tể các trạm y tế, kết quả thảo luận nhóm 
cũng cho thấy vai trò của mạng lưới cộng tác viên/y tế thôn bản trong việc hố trợ triển khai hoạt động.

Do hạn chế về nguồn lực trong nghiên cứu này, chúng tôi chỉ tiếp cận phỏng vấn sâu và thảo luận nhóm với đại diện các bên liên quan từ tuyến xã/phường (trạm y tế); tuyến quận/huyện (trung tâm y tế); tuyến tỉnh/thành phố (các bệnh viện, trung tâm kiểm soát bệnh tật, sở y tế); tuyến trung ương (đại diện chương trình PCUT), thay vì tiếp cận toàn bộ các bên liên quan đã xác định được thổng qua quá trình thảo luận nhóm.

\section{KẾT LUÂN}

Kết quả nghiên cứu cho thấy các bên liên quan đến chương trình sàng lọc từ trung ương đến địa phương, bao gồm Bộ y tế - vai trò chủ trì; bệnh viện $\mathrm{K}$ trung ương - vai trò điều phối chính của hoạt động, bộ tài chính và bộ kế hoạch đầu tư- vai trò huy động nguồn lực triển khai chương trìnhcơ sở y tế tuyến trung ương; bảo hiểm xã hội Việt Nam- vai trò quan trọng vì một trong những nguồn lực tài chính cở bản được xác định để triển khai chương trình một cách bền vứng và hiệu quả. Ở tuyến tỉnh, ủy ban nhân dân các tỉnh/thành phố - vai trò quyết định chủ trương triển khai chương trình sàng lọc, trung tâm kiểm soát bệnh tật/trung tâm y tế dự phòng tuyến tỉnh, bệnh viện tuyến tỉnhvà tuyến trung ương trong việc thực hiện kỹ thuật xét nghiệm và nội soi đại trực tràng để đảm bảo tính chính xác của kỹ thuật sàng lọc cũng như đảm bảo hạn chế các biến chứng của nội soi đại trực tràng. Ở tuyến xã/phường, vai trò của các trạm y tế xã/phường được nhấn mạnh trong việc triển khai hoạt động cùng với mạng lưới cộng tác viên/y tể thôn bản.

\section{TÀI LIỆ THAM KHẢO}

1. Bray F., Ferlay J., Soerjomataram I. và cộng sư. (2018). Global Cancer Statistics 2018: GLOBOCAN Estimates of Incidence and Mortality Worldwide for 36 Cancers in 185 Countries. CA Cancer J Clin.

2. Trân Văn Thuấn (2014), Báo cáo chuyên đề "Tình hình thực hiện dự án phòng chống ung thư", Hà Nội.

\title{
NHU CÂU VÀ KHẢ NĂNG CHI TRẢ CỦA NGƯờI DÂN VỚI CÁC DICCH VU CHĂM SÓC BAN NGÀY CHO NGƯỜI CAO TUỔI TAI MỘT KHU ĐÔ THI Ở HÀ Nô̂I NĂM 2021 VÀ MộI Số YẾU TỔ LIÊN QUAN
}

\author{
Bùi Thị Ngọc Minh ${ }^{1}$, Nguyễn Thị Lan Anh ${ }^{2}$, Nguyễn Thị Thu Trang ${ }^{3}$,
} Huỳnh Phước Thọ ${ }^{4}$, Nguyễn Lân Hiếu ${ }^{5}$, Lưu Ngọc Hoạt ${ }^{2}$.

\section{TÓM TẮT}

Dịch vụ chăm sóc ban ngày cho người cao tuổi (NCT) tại các khu đô thị ở các thành phố lớn đang là những vấn đề rất được quan tâm của nhiều gia đình, nhất là những người có bố me ở quê muốn đưa ra thành phố sống cùng con, cháu và các gia đình có NCT thường phải ở nhà môt mình. Để xác đinh được nhu cầu và khả năng chi trả cho dịch vụ này, chúng tôi đã triển khai một điều tra 201 chủ hố gia đình sống tại một số toà nhà được chọn ngấu nhiên trong khu chung cư An Lac, C1, C2 và C3 thuộc phường Câu Diễn, quận Nam Từ Liêm, Hà Nội. Kết quả phỏng vấn cho thây chỉ $5,5 \%$ chủ hộ không hưởng ứng mô hình

\footnotetext{
${ }^{1}$ Viện Đào tạo YHDP \& YTCC, Đại học Y Hà Nội Đại học Y Hà Nôi

${ }^{3}$ Trung tâm Y tể Quận Nam Từ Liêm

${ }^{4}$ Công ty Cổ phần eDoctor

${ }^{5}$ Bênh viên Đai hơ Y Hà Nôi

Chịu trách nhiệm chính: Bùi Thị Ngọc Minh

Email: buiminh.hn1629x@gmail.com

Ngày nhận bài: 22.2.2021

Ngày phản biên khoa hoc: 31.3.2021

Ngày duyệt bài: 9.4.2021
}

trung tâm chăm sóc sức khỏe (CSSK) ban ngày có phục hồi chức năng (PHCN) gần nơi ở của các cư dân, trong khi số người hưởng ứng và sẵn sàng chi trả là $68,2 \%$, số còn phân vân là $26,3 \%$. Về mô hình xây dựng các trung tâm vui chđ̛i, giải trí, giao lưu có kèm CSSKK ban ngày cho người cao tuối thì chỉ có $11 \%$ người được hỏi không hưởng ứng, số hưởng ứng và sắn sàng chi trả là $52,2 \%$, số còn phân vân là $36,8 \%$. Với các dịch vụ tại trung tâm chăm sóc ban ngày thì được ưa chuộng nhất là truyền thông nâng cao hiểu biết về sức khoẻ, bệnh tật, biết tự chăm sóc mình $(75,6 \%)$, tiếp đó là thể dục, dưỡng sinh $(73,6 \%)$, xoa bóp, bấm huyêtt, mát xa, xống hơi $(69,7 \%)$, cung cấp chế độ ăn uống khoa học $(64,2 \%)$, phục hồi chức năng $(60,2 \%)$, vui chơi, giải trí, giao lưu $(58,2 \%)$. Với mức giá đề xuất là 200.000 VNĐ/ngày cho các dịch vụ vui chơi, giải trí tai trung tâm (không bao gồm ăn uống, đi lại và chi phí cho các dịch vụ CSSK) thì có tới $45,8 \%$ đồng ý trả với mức giá này, 41 1, $8 \%$ muốn trả ở mức thấp hơn, tuy nhiên lại có $12,4 \%$ có thể trả cao hơn. Có mối liên quan có ý nghĩa thống kê giữa mức chi trả lớn hơn hoặc bằng mức giá 200.000 VNĐ/ngày với các yếu tố trình độ học vấn và nghề nghiệp của đối tượng nghiên cứu. Từ khóa: nhu cầu, khả năng chi trả, chăm sóc ban ngày, người cao tuổi. 